\title{
The effect of amoxicillin on dental enamel development in vivo
}

\author{
Juliana FELTRIN-SOUZA(a) in \\ Fabiano JEREMIAS(b) \\ Satu ALALUUSUA(c) \\ Carin SAHLBERG (c) iD \\ Lourdes SANTOS-PINTO(b) iD \\ Jukka JERNVALL(d) \\ Susanna SOVA(d) iD \\ Rita de Cássia Loiola \\ CORDEIRO(b) iD \\ Paulo Sérgio CERRI(e) \\ (a) Universidade Federal do Paraná - UFPR, \\ Department of Stomatology, Universidade \\ Federal do Paraná, Curitiba, PR, Brazil. \\ (b) Universidade Estadual Paulista - Unesp, \\ School of Dentistry, Department of Pediatric \\ Dentistry, Araraquara, SP, Brazil. \\ (c) University of Helsinki, School of Medicine, \\ Department of Oral and Maxillofacial \\ Diseases, Helsinki, Finland. \\ (d) University of Helsinki, Institute of \\ Biotechnology, Developmental Biology \\ Program, Helsinki, Finland. \\ (e) Universidade Estadual Paulista - Unesp, \\ School of Dentistry, Department of \\ Morphology, Araraquara, SP, Brazil.
}

Declaration of Interests: The authors certify that they have no commercial or associative interest that represents a conflict of interest in connection with the manuscript.

Corresponding Author:

Juliana Feltrin de Souza

E-mail: julianafeltrin@hotmail.com

https://doi.org/10.1590/1807-3107bor-2020.vol34.0116

Submitted: April 21, 2020

Accepted for publication: July 26, 2020

Last revision: July 31, 2020
Abstract: The exposure to amoxicillin has been associated with molar incisor hypomineralization. This study aimed to determine if amoxicillin disturbs the enamel mineralization in in vivo experiments. Fifteen pregnant rats were randomly assigned into three groups to received daily phosphatase-buffered saline or amoxicillin as either 100 or $500 \mathrm{mg} / \mathrm{kg}$. Mice received treatment from day 13 of pregnancy to day 40 postnatal. After birth, the offsprings from each litter continued to receive the same treatment according to their respective group. Calcium (Ca) and phosphorus (P) content in the dental hard tissues were analyzed from 60 upper first molars and 60 upper incisors by the complexometric titration method and colorimetric analysis using a spectrophotometer at $680 \mathrm{~nm}$, respectively. Lower incisors were analyzed by X-ray microtomography, it was measured the electron density of lingual and buccal enamel, and the enamel and dentin thickness. Differences in Ca and P content and electron density among the groups were analyzed by one-way ANOVA. There was no significant difference on enamel electron density and thickness among the groups $(p>0.05)$. However, in incisors, the higher dose of amoxicillin decreased markedly the electron density in some rats. There were no statistically significant differences in $\mathrm{Ca}(\mathrm{p}=0.180)$ or $\mathrm{P}$ content $(\mathrm{p}=0.054)$, although the higher dose of amoxicillin could affect the enamel in some animals. The amoxicillin did not significantly alter the enamel mineralization and thickness in rats.

Keywords: X-Ray Microtomography; Dental Enamel; Amoxicillin; Amelogenesis; Dental Enamel Hypoplasia.

\section{Introduction}

Enamel formation, also known as amelogenesis, is a complex process involving cellular proliferation and differentiation through interactions between epithelial and ectomesenchymal cells., ${ }^{1,2}$ Amelogenesis is mainly divided into three major stages:, secretory, transition, and maturation. During the secretory stage, ameloblasts secrete large quantity of matrix proteins (predominantly amelogenin), where the enamel crystals grow. Once the full thickness of enamel has been deposited, the cells undergo a short transitional stage into maturation. During the maturation stage, there is an increase in the matrix proteins degradation and completion of the mineralization process. ${ }^{1}$ 
Whereas tooth development is a genetically regulated, it is susceptible to detrimental influences of systemic and environmental factors. A highly regulated process of the secretion and the normal development of the organic enamel matrix is a prerequisite for formation of normal mineral crystals. ${ }^{3,4,5,6}$ Disturbances during the transition and maturation stages of amelogenesis can result in defects in the enamel structure and composition, such as hypomineralized enamel. ${ }^{6}$ In experimental studies using animals, pathological changes of the enamel surface have been reported as a result of exposure to toxic doses of several agents, including strontium, cobalt, fluoride, environmental toxicants (such as dioxins), and tetracycline. . $^{3,7}$

Amoxicillin use during early childhood has been associated with molar-incisor hypomineralization $(\mathrm{MIH}){ }^{39,10,11,12,13} \mathrm{MIH}$ is defined as a hypomineralization of systemic origin of one to four first permanent molars, frequently associated with involvement of the permanent incisors. ${ }^{14}$ In $\mathrm{MIH}$, porous enamel is susceptible to break down, mainly under the influence of masticatory forces, which leaves the dentin unprotected; and thus contributes to the development of carious lesions. ${ }^{14,15}$ The prevalence of MIH has been reported to range from 2.8 to $44 \%$ in different population. ${ }^{15,16,17,18}$ A clear etiology of $\mathrm{MIH}$ is yet to be defined. A multifactorial origin, in which the systemic factors act in synergism, has been suggested..$^{13,19}$ There are evidences that changes in gene expression during dental enamel formation may be responsible for $\mathrm{MIH} .{ }^{20,21}$

Several studies have described the microstructure of hypomineralized enamel as presenting less distinct prism sheaths and disorganized enamel. Moreover, the hardness and modulus of elasticity of enamel affected by hypomineralization have shown lower values than normal enamel. ${ }^{6,22,23}$ The chemical composition of molars affected by $\mathrm{MIH}$ is also changed. ${ }^{24,25,26}$

The use of amoxicillin alone, or associated with fluoride, affects amelogenesis in cultured mouse molars, resulting in reduced enamel thickness and delayed onset of the secretory stage by ameloblasts. ${ }^{3}$ In an in vivo study, dentin mineralization was found to be disturbed in rat molars after exposure to a single dose of amoxicillin. ${ }^{27}$ De Souza et al. evaluated the effect of amoxicillin during the secretory stage of the amelogenesis in rats, and reported that exposure to amoxicillin significantly reduced enamel thickness. However, these studies did not evaluate the mineral content of enamel treated with amoxicillin during tooth development. ${ }^{28}$

X-ray microtomography (micro-CT) has been employed for assessment of the severity of defects in enamel and other hard tissues. ${ }^{25,29}$ It provides high-resolution morphological information by means of an accurate and quantitative method. The micro-CT allows the imaging of structural details and quantitative analysis, such as measurement of mineral density in mineralized tissues. ${ }^{29}$

The enamel structure and chemical composition are complex, and different methods should be combined to evaluate them in a proper context taking into account the chemical and structural properties..$^{22}$ Therefore, the present in vivo investigation was carried out to assess if amoxicillin disturbs the enamel development in the incisors and first molars of rats using biochemical analyses of calcium and phosphorus content and micro-CT. Micro-CT was also used in assessing the thickness of enamel and dentin.

\section{Methodology}

\section{Animal care}

This study was performed in accordance with Brazilian animal care and national laws on animal use. The research protocol was authorized by the Ethical Committee for Animal Research (report \#34/2010). The study was reported according to ARRIVE guideline.

The samples were composed of fifteen female rats (Rattus norvegicus albinus, Holtzman), aged 2-3 months and weighing approximately $250 \mathrm{~g}$. The rats were maintained under controlled temperature $\left(23 \pm 1^{\circ} \mathrm{C}\right)$ and humidity $(55 \pm 5 \%)$, with a 12 -h/ $12 \mathrm{~h}$ light/dark cycle and food and water available ad libitum.

Female rats in estrous were mated overnight with males (two females per male). In the early morning, the male rat was removed from the cage. Vaginal smears were taken from female rats and analyzed under a light microscope (Carl Zeiss, Jenamed, Germany). The presence of sperm in the vaginal smear was 
deemed as pregnancy and designated as a first day of embryonic age.

The pregnant rats were single-housed in polypropylene cages and randomly distributed into three groups ( $n=5$ per group). In the control group, the rats received phosphatase-buffered saline (PBS). In the A100 group (A100), the rats received oncedaily, oral dosing of $100 \mathrm{mg} / \mathrm{kg}$ amoxicillin. In the A500 group (A500), the rats received once-daily, oral dosing of $500 \mathrm{mg} / \mathrm{kg}$ amoxicillin. The $500 \mathrm{mg} / 5 \mathrm{~mL}$ amoxicillin was purchase from Eurofarma Genéricos; São Paulo, SP, Brazil. Animals were treated with PBS or amoxicillin $(100 \mathrm{mg} / \mathrm{kg}$ or $500 \mathrm{mg} / \mathrm{kg})$ at the same final volume via gavage, as described on Souza et al..$^{28}$

The treatments were performed from day 13 of pregnancy, which corresponds to the beginning of development of the first upper molars in rats and when amoxicillin crosses the placenta and umbilical cord. ${ }^{28,30}$ After birth, the offsprings from each litter continued to receive the same treatment according to their respective group, phosphatase-buffered saline (PBS), $100 \mathrm{mg} / \mathrm{kg}$ amoxicillin (A100) or $500 \mathrm{mg} / \mathrm{kg}$ amoxicillin (A500), from postnatal day 1 until postnatal day 40, as described on Souza et al. ${ }^{28}$ On day 40, a total of ten offspring per group were euthanized by an overdose of $10 \%$ ketamine (Cetamin ${ }^{\circledR}$, Syntec do Brasil Ltda, São Paulo, Brazil), and 2\% xylazine hydrochloride (Xilazin ${ }^{\circledR}$, Syntec do Brasil Ltda, São Paulo, Brazil). The upper and lower jaws were extracted, cleaned, and coded for analyses.

\section{Micro-CT analyses}

Lower jaws of 15 animals, five from each group (A100, A500 and control) were randomly selected and examined by $\mathrm{X}$-ray microtomography. The jaws were cleaned, dehydrated, and scanned using a SkyScan 1272 desktop micro-CT system (Bruker microCT N.V., Kontich, Belgium). The samples were imaged with $90 \mathrm{kV}$ acceleration voltages and a source current of $111 \mu \mathrm{A}$. The filter applied was $\mathrm{Al} 0.5+\mathrm{Cu} 0.038$, and the scaled image pixel size was $20 \mu \mathrm{m}(0.05 \mathrm{pixel} / \mu \mathrm{m})$. Projections were acquired over a full circle of rotation steps at 0.4 degrees angle intervals, and each projection was composed of the average of 4 transmission images. The data from the tomography projection scans were reconstructed using SkyScan NRecon and then analyzed using ImageJ (Wayne Rasband, National Institutes of Health, USA) software. Two minerals, fluorapatite $\left(\mathrm{Ca}_{5}\left(\mathrm{PO}_{4}\right)_{3} \mathrm{~F}\right)$ and quartz $\left(\mathrm{SiO}_{2}\right)$ were used for standardization and calibration of measurements. The mean gray-value of the mineral grains were set to as the electron densities of $3.17 \mathrm{~g} / \mathrm{cm}^{3}$ (fluorapatite) and $2.65 \mathrm{~g} / \mathrm{cm}^{3}$ (quartz). From the first molars, lingual and buccal enamel densities from the thickest areas were measured (Table 1). From the incisors, the measurements were made along a straight $200-\mu \mathrm{m}$ wide rectangle area along the length of the enamel that reached from the mesial surface of the first molar to the tip of the incisor to a length of $10000 \mu \mathrm{m}$. The outermost tips of the incisors were disregarded because the wear of the rat teeth and abrasion of the enamel influences the values (Figure 1). The analysis was performed once in each tooth due to the high accuracy measurements of the micro CT. ${ }^{22,25,29,31}$ The thickness of enamel and dentin and the electron density of dentin were measured from the CT-scans' central section of the incisors at the point just in front of the margin of the lower jaw bone (Figure 2).

\section{Biochemical analysis for determination of calcium and phosphorus content}

For determination of calcium $(\mathrm{Ca})$ and phosphorus (P) content in the dental hard tissues, a total of 60 upper first molars and 60 upper incisors from the randomly selected 30 animals (10 animals per group) were dried, separately, for $24 \mathrm{~h}$ at $60^{\circ} \mathrm{C}$, then pulverized. The resulting powder was sieved to obtain particles in the range of 140 to $1.000 \mu \mathrm{m}$ and dried at $60^{\circ} \mathrm{C}$ for an additional $24 \mathrm{~h}$. Aliquots $(30 \pm 0.01 \mathrm{mg})$ were then

Table 1. Mean (SD) electron density on the lingual and buccal surfaces of the molars in each group. A100 = amoxicillin $100 \mathrm{mg} / \mathrm{kg} /$ day and A500 = amoxicillin $500 \mathrm{mg} / \mathrm{kg} /$ day.

\begin{tabular}{lcc}
\hline \multirow{2}{*}{ Groups } & \multicolumn{2}{c}{ Electron density } \\
\cline { 2 - 3 } & \multicolumn{1}{c}{ Lingual } & Buccal \\
\cline { 2 - 3 } Control & Mean (SD) & Mean (SD) \\
A100 & $2.95(0.04)$ & $2.95(0.04)$ \\
A500 & $2.99(0.04)$ & $2.96(0.02)$ \\
\hline
\end{tabular}

No significant difference between the three groups $(p>0.05$, ANOVA). SD: standard deviation. Electron density in $\mathrm{cm}^{3}$. 

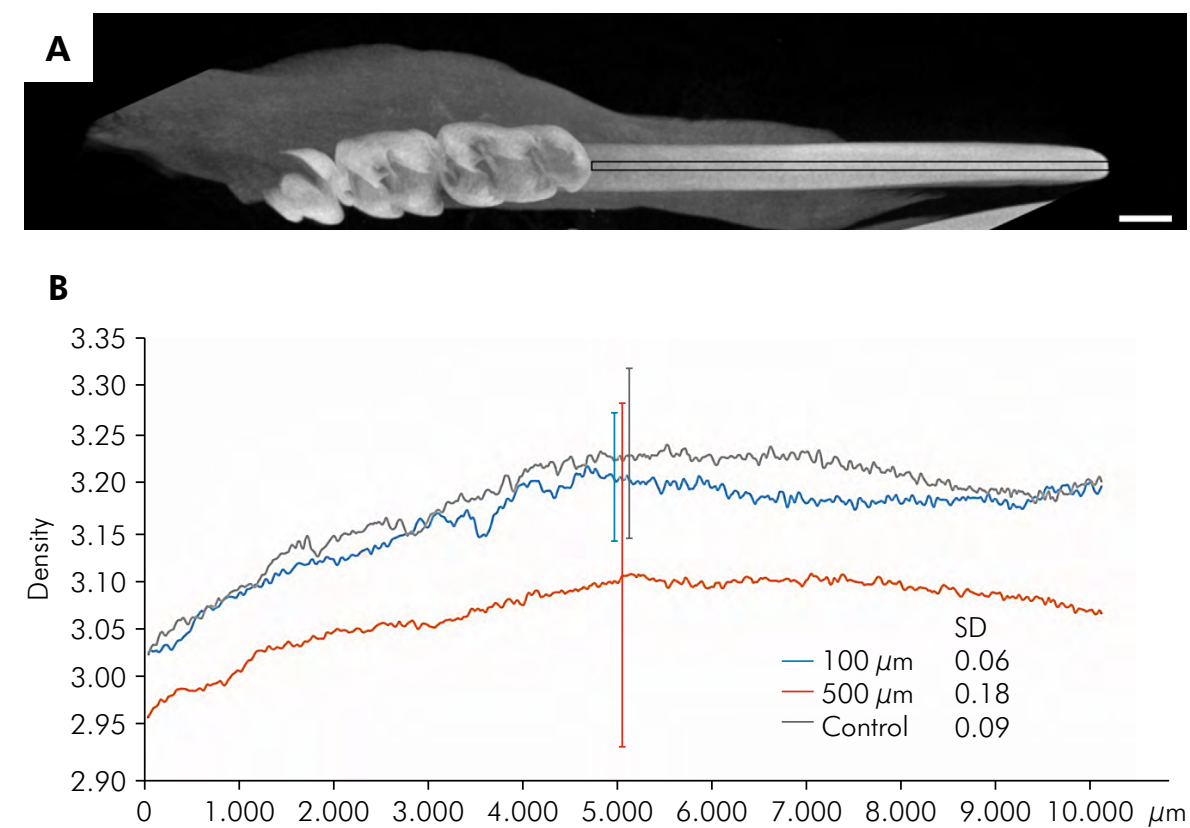

Figure 1. A. ImageJ projection of a half mandible and right side incisor from a rat given $100 \mathrm{mg} / \mathrm{kg}$ amoxicillin. Inserted the area from which the density was measured. bar: $10000 \mu \mathrm{m}$, white dashed line represents the area used to calculate the SD reported in Figure 1B. B. Scatter plot of mean enamel density values from five incisors/experiment. The measurement was made from the mesial surface of the first molar towards the tip of the incisor. The SD was measured at $5000 \mu \mathrm{m}$ from the molar mesial surface, approximately at the point where the incisor enamel has reached full mineralization (dashed line in A).
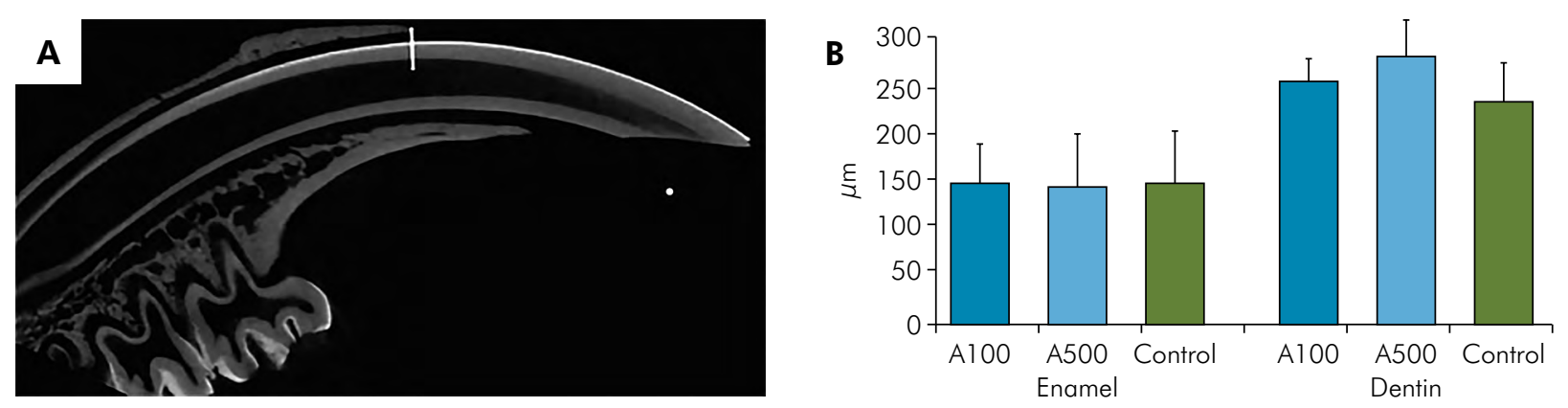

Figure 2. A. Longitudinal section of an incisor exposed to $100 \mathrm{mg} / \mathrm{kg}$ amoxicillin. The white bar indicates the point of measurement. B. A graphical representation of mean thickness of enamel and dentin with confidence intervals (95\% Cl). There are no significant differences between the groups. A100 = amoxicillin $100 \mathrm{mg} / \mathrm{kg} /$ day and A500 = amoxicillin $500 \mathrm{mg} / \mathrm{kg}$ day.

weighed out and transferred to tubes containing $1.0 \mathrm{~mL}$ of $0.5 \mathrm{M}$ nitric acid. After $1 \mathrm{~h}$, this solution was divided into two parts for $\mathrm{Ca}$ and $\mathrm{P}$ determination. The $\mathrm{Ca}$ content was quantified by complexometric titration. EDTA (disodium ethylenediaminetetraacetate) and the indicator Calcon ${ }^{\circledR}$ (Sigma-Aldrich, St. Louis, USA), were added to the sample. The Ca content was expressed as mg of Ca per $\mathrm{g}$ of tooth mass (mg Ca/g tooth). The P content was determined by the colorimetric method using a spectrophotometer at $680 \mathrm{~nm}$ (DR 2500, Hack, Loveland, USA). Sodium molybdate $(10 \mathrm{~mL})$ and $5 \mathrm{M}$ ascorbic acid $(1.0 \mathrm{~mL})$ were added to the sample. The spectrophotometer had been previously calibrated with standards of known $\mathrm{P}$ concentration. The P content was expressed as $\mathrm{mg} \mathrm{P} / \mathrm{g}$ tooth. The analyses were performed three times in each specimen and the mean of the three measures was given as results.

The Micro-CT analyzes, and the biochemical analysis for determination of Calcium and Phosphorus 
content were performed after due training and their interpretations made by an expert researcher.

\section{Statistical analysis}

The data was analyzed using the Statistica version 8.0 software (StatSoft Inc, Tulsa, USA). The dependent variables were represented by the values of $\mathrm{Ca}$ and $\mathrm{P}$ content and electron density, which were analyzed according the values distribution by Kolmogorov-Smirnov test. The values of $\mathrm{Ca}, \mathrm{P}$ and electron density presented a normal distribution $(p>0.05)$. The dependent variables were compared among the groups (independent variables) by one-way ANOVA. The significance level of $5 \%$ was adopted. Additionally, to obtain exact $p$ values, we tested electron density differences in the incisor micro-CT data after treatment assignments were randomized 10,000 times (means of density values from 0 to $10 \mathrm{~mm}$ towards the incisor tip).

\section{Results}

The mean (SD) of enamel electron densities on the buccal and lingual surfaces of the lower first molars for the control, A100 and A500 groups are given in Table 1 . The statistical analysis showed that there was no significant difference among the groups $(\mathrm{p}>0.05)$.

Scatter plot presents the mean of density values (SD) from each incisor group (Figure 1B). At the point where the incisor enamel has reached full mineralization, (approximately $5000 \mu \mathrm{m}$ from the molar mesial surface) the density values of the controls ranged from 3.14 to $3.31 \mathrm{~g} / \mathrm{cm}^{3}$ and those of the A100 group from 3.12 to $3.20 \mathrm{~g} / \mathrm{cm}^{3}$. Enamel's electron densities in the A500 rats ranged from 2.93 to $3.30 \mathrm{~g} / \mathrm{cm}^{3}$. The values of A500 group were marginally different from the other groups $(p=0.081)$.
The thickness of enamel and dentin was measured from the micro-CT scans (Figure 2). There was no significant difference in enamel thickness among the three groups and only a slightly greater thickness of dentin was observed in rats exposed to $500 \mathrm{mg} / \mathrm{kg} / \mathrm{d}$ amoxicillin. Electron density values of dentin were very similar to the mean, 2.84, 2.84 and $2.83 \mathrm{~g} / \mathrm{cm}^{3}$ in the control, A100 and A500 groups, respectively.

Statistically significant differences in the Ca and $\mathrm{P}$ content were not observed among the groups $(\mathrm{p}>0.05)$ (Table 2).

\section{Discussion}

Amoxicillin useinearly childhood has been associated with molar-incisor hypomineralization. ${ }^{3,910,11,12,13}$ In vitro studies have demonstrated changes in cultured mouse embryonic tooth explants after amoxicillin exposure. ${ }^{3,12}$ In our previous study, same doses of amoxicillin reduced the enamel matrix thickness during secretory stage. ${ }^{28}$ However, the effect of amoxicillin exposure in vivo on the mineral content of rat teeth was unclear.

According to Schour and Massler, ${ }^{30}$ the first rat molars begins its formation by day 13 of intrauterine life, and its mineralization is completed on day 12 . In the present study, the animals were exposed to amoxicillin during every stage of amelogenesis until day 40. At this age, the enamel of the incisors is $80 \mu \mathrm{m}$ thick, allowing manipulation and mineral content analysis. ${ }^{30}$ The doses of 100 and $500 \mathrm{mg} / \mathrm{kg} / \mathrm{d}$ amoxicillin were selected to simulate amoxicillin exposure in children during the first years of life pursuant to recommendations of the American Academy of Pediatrics Subcommittee on Management of Acute Otitis. ${ }^{32}$ Since rat and human metabolism are different, it is necessary a higher dose of amoxicillin to determine its effect on the development of dental

Table 2. Mean (SD) Calcium (Ca) and Phosphorus (P) content in $\mathrm{mg} / \mathrm{g}$ of tooth. $\mathrm{A} 100=$ amoxicillin $100 \mathrm{mg} / \mathrm{kg} / \mathrm{d}$ and A500 = amoxicillin 500 mg $/ \mathrm{kg} / \mathrm{d}$.

\begin{tabular}{lcccc}
\hline \multirow{2}{*}{ Group } & \multicolumn{2}{c}{ Calcium } & \multicolumn{2}{c}{ Phosphorus } \\
\cline { 2 - 5 } & Incisors & Molars & Incisors & Molars \\
\hline Control & $271.0(18.1)$ & $258.9(36.7)$ & $135.1(7.0)$ & $136.1(5.7)$ \\
A100 & $289.2(17.3)$ & $258.3(27.2)$ & $133.6(6.7)$ & $133.1(5.3)$ \\
A500 & $260.1(16.2)$ & $250.2(58.8)$ & $136.0(6.9)$ & $143.1(7.5)$ \\
\hline
\end{tabular}

No significant difference among the three groups ( $p>0.05$, ANOVA). SD: standard deviation. 
enamel in rats; this approach was also used in previous studies to evaluate the effect of other substances such as fluoride, macrolides and other factors in amelogenesis. ${ }^{7,33,34}$

Dental enamel has a number of properties that makes it a unique structure. It is the hardest structure in the mammalian body and has a very high proportion of inorganic matter, mainly hydroxyapatite. The ameloblasts have limited reparative capacity; therefore, disturbances during the mineralization of enamel can result in permanent defects in enamel structure. Defects in mature enamel have important implications in understanding their relation with etiological factors. ${ }^{22}$

During amelogenesis, elements and compounds are transported to mineralizing areas. ${ }^{35}$ The elemental composition pattern of dental enamel varies during the differentiation stages of the ameloblasts. ${ }^{1,7}$ Calcium and phosphorus, in the form of phosphate, are the major components of hydroxyapatite in all hard tissues. Studies have been using the $\mathrm{Ca} / \mathrm{P}$ ratio to determine the calcium content of hard tissues, which was found to be constant along the developing tooth organ..$^{22,24,26}$ If this ratio is altered, it is likely that the mineral phase is altered or that significant ion substitution may have occurred. ${ }^{24}$

Several methods can be used to quantify the mineral content of hypomineralized enamel. ${ }^{22,25,29} \mathrm{The}$ present study utilized quantitative chemical analysis and micro-CT to determine the mineralization state of enamel after amoxicillin exposure. Micro-CT provides a high-resolution, non-destructive, and non-invasive method for the analysis of dental hard tissues. This method promotes the three-R, the replacement, refinement e reduction of animal samples. It has been constantly cited as a reliable method for measurement of the mineral density of normal and hypomineralized enamel. ${ }^{22,25,29,31}$

In the present study, the amoxicillin-treated groups did not differ significantly from the control group in the calcium and phosphorus content, suggesting that amoxicillin exposure did not influence the mineralization and maturation stages. Studies in vitro with mouse molar germs have demonstrated that amoxicillin affects ameloblasts during the secretory stage, causing alterations in ameloblast morphology and promoting a reduction in the enamel matrix.,12,36 Similarly, mice exposed to amoxicillin/clavulanic acid (50, 100 or $150 \mathrm{mg} / \mathrm{kg} /$ day) showed increase in the amount of disorganization and clear vacuoles in maturation stage ameloblasts. ${ }^{34}$ In another in vivo study, the animals exposed to amoxicillin (100 or $500 \mathrm{mg}$ / $\mathrm{kg} / \mathrm{d}$ ) during the secretory stage of amelogenesis (7-day-old-rats), presented a significant reduction in the enamel thickness. Otherwise, the enamel thickness in the amoxicillin-treated rats did not differ from the control group during mineralization stage (12-day-old-rats), ${ }^{28}$ supporting our results. In conclusion, these suggest that ameloblasts are especially sensitive to amoxicillin exposure during the secretory stage, but not during the mineralization stage. Fluoride exposition has also been observed to influence the ameloblasts and enamel formation at different stages of the life cycle, resulting in distinct enamel defects types. ${ }^{7}$

Another point is the possible recovery of ameloblasts during mineralization. There is evidence that rat pups exposed to a calcium-deficient diet developed enamel hypomineralization in incisors, with thinner crystallites and presence of organic matrix. ${ }^{37}$ However, when normal diet was returned, enamel mineralization was restored. ${ }^{37}$

Recently, an in vivo study has reported structural changes in the enamel development of mice incisors after chronic administration via subcutaneous injections of amoxicillin and clavulanic acid. ${ }^{34}$ Significant reduction in the mineral content of calcium, fluoride and phosphate was also detected by X-ray spectroscopy analysis. These results are not in line with our findings probably due to the clavulanic acid that could act in synergism with amoxicillin interfering with the enamel formation. We also used a different route of administration of amoxicillin.

Another concern is the mineral content analysis of enamel defects and its implications. In human, the molars affected by MIH have shown lower hardness than normal enamel due to the disorganized structure of the hypomineralized enamel; however, mineral content findings were controversial. ${ }^{22,25,38}$ Some studies have reported that molars affected by MIH exhibited lower calcium and phosphorus 
content than in enamel of the control group. ${ }^{25,26}$ On the other hand, other studies have shown that $\mathrm{Ca} / \mathrm{P}$ ratio in enamel affected by $\mathrm{MIH}$ was similar to control molars. ${ }^{22,24}$ Similar results were found by Sucheela and Bhatnagar ${ }^{8}$ evaluating fluoride exposure in rabbits and rats. It is possible that, in hypomineralized enamel, calcium and phosphorus are presented not only in an organized crystalline structure but also in amorphous matter. ${ }^{8,24}$ Thus, mineral content should be interpreted with caution, and additional methods should be combined for its analysis. Also it is generally accepted that the serum calcium concentration is controlled within a very narrow range by hormones, such as calcitonin and parathyroid hormone, and it plays important role in the maintenance of a normal heart beat as well as mineralized tissue metabolism. ${ }^{31}$

A recent study evaluated if treatment with antibiotics and non-steroidal anti-inflammatory drugs could disturb the enamel mineralization in mice. ${ }^{39}$ The authors evaluated amoxicillin $(5 \mathrm{mg} / \mathrm{d}$ of amoxicillin), amoxicillin/clavulanate $(2.5 / 0.31 \mathrm{mg} / \mathrm{d})$, erythromycin $(5 \mathrm{mg} / \mathrm{d})$, acetaminophen $(5 \mathrm{mg} / \mathrm{d})$, ibuprofen $(2.5 \mathrm{mg} / \mathrm{d})$ and celecoxib $(0.12 \mathrm{mg} / \mathrm{d})$ on the $\mathrm{Ca}, \mathrm{P}, \mathrm{Al}, \mathrm{K}, \mathrm{Na}, \mathrm{Mg}$ and $\mathrm{Cl}$ content by EDX-analysis, as well as on the COX2 expression. The amoxicillin groups did have any effect on the calcium and phosphate content, in agreement with our results. The authors suggested that COX2 is involved on the enamel formation. Amoxicillin, amoxicillin/ clavulanate and erythromycin administration reduced the quantity of COX2 present in the enamel organ of mouse incisor during the maturation period, but not its activity.

In the present study, electron density values in the molars ranged from 2.83 to $2.99 \mathrm{~g} / \mathrm{cm}^{3}$. These values were similar to the electron density of normal human enamel, which is approximately 2.8 to $3.0 \mathrm{~g} / \mathrm{cm}^{3,29}$ Molar surfaces, which have been severely affected by $\mathrm{MIH}$, have shown reductions of up to $20 \%$ in mineral density when compared to normal enamel. ${ }^{25}$ Our findings corroborate with a recent study, which evaluated the effect of amoxicillin (doses of $50 \mathrm{mg}$ / $\mathrm{kg} / \mathrm{d}$ and $90 \mathrm{mg} / \mathrm{kg} / \mathrm{d}$ ) in enamel mineral content in piglets. ${ }^{40}$ The authors did not observe significant differences between the groups. In this study, the electron density values of enamel in the molars of controls and treated piglets were lower than ours and ranged from 2.41 to $2.66 \mathrm{~g} / \mathrm{cm}^{3}$.

We found that the enamel of incisors presented more variation of electron density values than the molars. It could be explained by the differences on the enamel developmental of the incisors, which presents a continuous metabolism and growth. Although no significant difference was detected, the A500 group presented lower values of densities in some animals $(p=0.08)$ in the incisors. However, the variability between the animal response to the exposure could be due the biological variability and sensitivity among the experimental animals in developing defects of enamel, which appeared first in rats exposed to a higher dose of amoxicillin. Kumazava et al. ${ }^{27}$ reported that the intensity of dentin alteration was observed to vary between rats in an amoxicillin-treated group depending on individual differences, particularly body weight. This may explain the greater variability observed in the A500 group during our study.

In this study, the sex information of the offspring was not collected. Although it can be a limitation, to the best of our knowledge, there is no evidence that sex is associated to dental enamel defects. The data of $\mathrm{Ca}$ and $\mathrm{P}$ have small variation, the difference in mean values of $\mathrm{Ca}$ and $\mathrm{P}$ among the groups were also small, thus a larger sample size may provide a statistically significant result. However, our sample size was similar to previous studies in animals. ${ }^{8,27,34}$

\section{Conclusion}

Electron density in molars was similar among the groups. In incisors, the higher dose of amoxicillin decreased markedly the electron density in some rats, but the difference among the groups was not statistically significant. Further studies are needed to understand the amoxicillin effects on the maturation stage of enamel.

\section{Acknowledgments}

We thank Aki Kallonen for his assistance. This study was supported by FAPESP under grant (Proc.: 2013/13569-6), CAPES and the Academy of Finland. 
The effect of amoxicillin on dental enamel development in vivo

\section{References}

1. Nanci A. Enamel: composition, development and structure. In: Nanci A, editor. Ten cate's oral histology, development, structure, and function. 8th ed. Rio de Janeiro: Elsevier; 2008. p. 141-90.

2. Thesleff I, Keränen S, Jernvall J. Enamel knots as signaling centers linking tooth morphogenesis and odontoblast differentiation. Adv Dent Res. 2001 Aug;15(1):14-8. https://doi.org/10.1177/08959374010150010401

3. Sahlberg C, Pavlic A, Ess A, Lukinmaa PL, Salmela E, Alaluusua S. Combined effect of amoxicillin and sodium fluoride on the structure of developing mouse enamel in vitro. Arch Oral Biol. 2013 Sep;58(9):1155-64. https://doi.org/10.1016/i.archoralbio.2013.03.007

4. Thesleff I. The genetic basis of tooth development and dental defects. Am J Med Genet A. 2006 Dec;140(23):2530-5. https://doi.org/10.1002/ajmg.a.31360

5. Gao Y, Sahlberg C, Kiukkonen A, Alaluusua S, Pohjanvirta R, Tuomisto J, et al. Lactational exposure of Han/Wistar rats to 2,3,7,8-tetrachlorodibenzo-p-dioxin interferes with enamel maturation and retards dentin mineralization. J Dent Res. 2004 Feb;83(2):139-44. https://doi.org/10.1177/154405910408300211

6. Suckling GW, Nelson DG, Patel MJ. Macroscopic and scanning electron microscopic appearance and hardness values of developmental defects in human permanent tooth enamel. Adv Dent Res. 1989 Sep;3(2):219-33. https://doi.org/10.1177/08959374890030022301

7. Bronckers AL, Lyaruu DM, DenBesten PK. The impact of fluoride on ameloblasts and the mechanisms of enamel fluorosis. J Dent Res. 2009 Oct;88(10):877-93. https://doi.org/10.1177/0022034509343280

8. Susheela AK, Bhatnagar M. Fluoride toxicity: a biochemical and scanning electron microscopic study of enamel surface of rabbit teeth. Arch Toxicol. 1993;67(8):573-9. https://doi.org/10.1007/BF01969271

9. Wuollet E, Laisi S, Salmela E, Ess A, Alaluusua S. Molar-incisor hypomineralization and the association with childhood illnesses and antibiotics in a group of Finnish children. Acta Odontol Scand. 2016 Jul;74(5):416-22. https://doi.org/10.3109/00016357.2016.1172342

10. Souza JF, Costa-Silva CM, Jeremias F, Santos-Pinto L, Zuanon AC, Cordeiro RC. Molar incisor hypomineralisation: possible aetiological factors in children from urban and rural areas. Eur Arch Paediatr Dent. 2012 Aug;13(4):164-70. https://doi.org/10.1007/BF03262865

11. Hong L, Levy SM, Warren JJ, Broffitt B. Amoxicillin use during early childhood and fluorosis of later developing tooth zones. J Public Health Dent. 2011;71(3):229-35. https://doi.org/10.1111/j.1752-7325.2011.00254.x

12. Laisi S, Ess A, Sahlberg C, Arvio P, Lukinmaa PL, Alaluusua S. Amoxicillin may cause molar incisor hypomineralization. J Dent Res. 2009 Feb;88(2):132-6. https://doi.org/10.1177/0022034508328334

13. Alaluusua S. Aetiology of Molar-Incisor Hypomineralisation: A systematic review. Eur Arch Paediatr Dent. 2010 Apr;11(2):53-8. https://doi.org/10.1007/BF03262713

14. Weerheijm KL, Jälevik B, Alaluusua S. Molar-incisor hypomineralisation. Caries Res. 2001 Sep-Oct;35(5):390-1. https://doi.org/10.1159/000047479

15. Jeremias F, Souza JF, Silva CM, Cordeiro RC, Zuanon AC, Santos-Pinto L. Dental caries experience and Molar-Incisor Hypomineralization. Acta Odontol Scand. 2013 May-Jul;71(3-4):870-6. https://doi.org/10.3109/00016357.2012.734412

16. Costa-Silva CM, Jeremias F, Souza JF, Cordeiro RC, Santos-Pinto L, Zuanon AC. Molar incisor hypomineralization: prevalence, severity and clinical consequences in Brazilian children. Int J Paediatr Dent. 2010 Nov;20(6):426-34. https://doi.org/10.1111/i.1365-263X.2010.01097.x

17. Soviero V, Haubek D, Trindade C, Da Matta T, Poulsen S. Prevalence and distribution of demarcated opacities and their sequelae in permanent 1st molars and incisors in 7 to 13-year-old Brazilian children. Acta Odontol Scand. 2009;67(3):170-5. https://doi.org/10.1080/00016350902758607

18. Weerheijm KL, Groen HJ, Beentjes VE, Poorterman JH. Prevalence of cheese molars in eleven-year-old Dutch children. ASDC J Dent Child. 2001;68(4):259-62.

19. Silva MJ, Scurrah KJ, Craig JM, Manton DJ, Kilpatrick N. Etiology of molar incisor hypomineralization - A systematic review. Community Dent Oral Epidemiol. 2016 Aug;44(4):342-53. https://doi.org/10.1111/cdoe.12229

20. Vieira AR, Kup E. On the etiology of molar-incisor hypomineralization. Caries Res. 2016;50(2):166-9. https://doi.org/10.1159/000445128

21. Jeremias F, Koruyucu M, Küchler EC, Bayram M, Tuna EB, Deeley K, et al. Genes expressed in dental enamel development are associated with molar-incisor hypomineralization. Arch Oral Biol. 2013 Oct;58(10):1434-42. https://doi.org/10.1016/i.archoralbio.2013.05.005

22. Fagrell TG, Dietz W, Jälevik B, Norén JG. Chemical, mechanical and morphological properties of hypomineralized enamel of permanent first molars. Acta Odontol Scand. 2010 Jul;68(4):215-22. https://doi.org/10.3109/00016351003752395

23. Xie ZH, Mahoney EK, Kilpatrick NM, Swain MV, Hoffman M. On the structure-property relationship of sound and hypomineralized enamel. Acta Biomater. 2007 Nov;3(6):865-72. https://doi.org/10.1016/i.actbio.2007.05.007

24. Mahoney EK, Rohanizadeh R, Ismail FS, Kilpatrick NM, Swain MV. Mechanical properties and microstructure of hypomineralised enamel of permanent teeth. Biomaterials. 2004 Sep;25(20):5091-100. https://doi.org/10.1016/j.biomaterials.2004.02.044 
Feltrin-Souza J, Jeremias F, Alaluusua S, Sahlberg C, Santos-Pinto L, Jernvall J, et al.

25. Fearne J, Anderson P, Davis GR 3rd. 3D X-ray microscopic study of the extent of variations in enamel density in first permanent molars with idiopathic enamel hypomineralisation. Br Dent J. 2004 May;196(10):634-8. https://doi.org/10.1038/sj.bdj.4811282

26. Jälevik B, Odelius H, Dietz W, Norén J. Secondary ion mass spectrometry and X-ray microanalysis of hypomineralized enamel in human permanent first molars. Arch Oral Biol. 2001 Mar;46(3):239-47. https://doi.org/10.1016/S0003-9969(00)00113-8

27. Kumazawa K, Sawada T, Yanagisawa T, Shintani S. Effect of single-dose amoxicillin on rat incisor odontogenesis: a morphological study. Clin Oral Investig. 2012 Jun;16(3):835-42. https://doi.org/10.1007/s00784-011-0581-4

28. Souza JF, Gramasco M, Jeremias F, Santos-Pinto L, Giovanini AF, Cerri PS, et al. Amoxicillin diminishes the thickness of the enamel matrix that is deposited during the secretory stage in rats. Int J Paediatr Dent. 2016 May;26(3):199-210. https://doi.org/10.1111/ipd.12184

29. Farah R, Drummond B, Swain M, Williams S. Linking the clinical presentation of molar-incisor hypomineralisation to its mineral density. Int J Paediatr Dent. 2010 Sep;20(5):353-60. https://doi.org/10.1111/j.1365-263X.2010.01061.x

30. Schours I, Massler M. The teeth. In: Farris EJ, Griffith JQ, editors. The rat in laboratory investigation. New York: Hafner; 1963. p. 104-60.

31. Fujita Y, Goto S, Ichikawa M, Hamaguchi A, Maki K. Effect of dietary calcium deficiency and altered diet hardness on the jawbone growth: a micro-CT and bone histomorphometric study in rats. Arch Oral Biol. 2016 Dec;72:200-10. https://doi.org/10.1016/i.archoralbio.2016.08.036

32. American Academy of Pediatrics, Subcommittee on Management of Acute Otitis Media. Diagnosis and management of acute otitis media. Pediatrics. 2004 May;113(5):1451-65. https://doi.org/10.1542/peds.113.5.1451

33. Chesa-Jiménez J, Peris JE, Torres-Molina F, Granero L. Low bioavailability of amoxicillin in rats as a consequence of presystemic degradation in the intestine. Antimicrob Agents Chemother. 1994 Apr;38(4):842-7. https://doi.org/10.1128/AAC.38.4.842

34. Mihalaş E, Matricala L, Chelmuş A, Ghęu N, Petcu A, Paşca S. The role of chronic exposure to amoxicillin/clavulanic acid on the developmental enamel defects in mice. Toxicol Pathol. 2016 Jan;44(1):61-70. https://doi.org/10.1177/0192623315610822

35. Cerri PS, Faria FP, Villa RG, Katchburian E. Light microscopy and computer three-dimensional reconstruction of the blood capillaries of the enamel organ of rat molar tooth germs. J Anat. 2004 Mar;204(Pt 3):191-5. https://doi.org/10.1111/i.0021-8782.2004.00268.x

36. Mostafa HM, Shehata FI, Omar SO, Kawana KY. The effect of amoxicillin on the secretory stage of amelogenesis in rats. Alex Dent J. 2020;45:34038.

37. Lozupone E, Favia A. Morphometric analysis of the deposition and mineralization of enamel and dentine from rat incisor during the recovery phase following a low-calcium regimen. Arch Oral Biol. 1994 May;39(5):409-16. https://doi.org/10.1016/0003-9969(94)90171-6

38. Jälevik B. Enamel hypomineralization in permanent first molars: a clinical, histo-morphological and biochemical study. Swed Dent J Suppl. 2001;(149):1-86.

39. Hu XP, Li ZQ, Zhou JY, Yu ZH, Zhang JM, Guo ML. Analysis of the association between polymorphisms in the vitamin D receptor (VDR) gene and dental caries in a Chinese population. Genet Mol Res. 2015 Sep;14(3):11631-8. https://doi.org/10.4238/2015.September.28.15

40. Kuscu OO, Sandalli N, Dikmen S, Ersoy O, Tatar I, Turkmen I, et al. Association of amoxicillin use and molar incisor hypomineralization in piglets: visual and mineral density evaluation. Arch Oral Biol. 2013 Oct;58(10):1422-33. https://doi.org/10.1016/i.archoralbio.2013.04.012 